\title{
Guerreiras do Cárcere: Uma Rede Virtual de Apoio aos Familiares de Pessoas Privadas de Liberdade
}

\author{
Mariana Barcinski ${ }^{1}$ \\ Helena Salgueiro Lermen \\ Programa de Pós-Graduação em Psicologia da Pontifícia Universidade Católica \\ do Rio Grande do Sul, Porto Alegre, Rio Grande do Sul, Brasil \\ Cristiane Campani \\ Bibiana Altenbernd \\ Faculdade de Psicologia da Pontifícia Universidade Católica do Rio Grande do Sul, \\ Porto Alegre, Rio Grande do Sul, Brasil
}

\begin{abstract}
Resumo
$\mathrm{O}$ artigo tem como objetivo investigar as funções desempenhadas por uma rede informal de apoio para familiares de pessoas privadas de liberdade, constituída por uma comunidade em uma das maiores redes sociais de relacionamento do mundo. Durante uma semana selecionamos postagens realizadas na referida comunidade; estas foram agrupadas em categorias interpretativas que remetem às funções de uma rede de apoio social, tais como descritas pela literatura. A análise das postagens foi conduzida a partir da Análise Crítica do Discurso, que busca entender de que forma as produções discursivas refletem relações sociais de poder. Questões de gênero estão no foco da análise desta rede virtual, constituída quase que exclusivamente por mulheres. Neste sentido, enfatizamos o processo singular de constituição subjetiva das participantes e as expectativas sociais atreladas a elas nas trocas virtuais que caracterizam este espaço de compartilhamento como eminentemente feminino. Os resultados apontam que as trocas efetuadas entre os participantes procuram suprir diversas demandas dos familiares, tais como as de apoio emocional, jurídico e material. A referida comunidade reflete a fragilidade das redes de apoio das famílias de pessoas privadas da liberdade, o potencial criativo e as possibilidades de superação das dificuldades encontradas no contexto carcerário.
\end{abstract}

Palavras-chave: Gênero, prisão, rede de apoio social.

\section{Prison's Warriors: A Virtual Support Network for Families of Freedom Deprived People}

\begin{abstract}
The present paper aims at investigating the roles played by an informal support network for families of incarcerated people. This network is constituted as a group in one of the largest social networks in the world. We selected the posts found in one week in the referred group; these were then grouped in interpretive categories that define the roles usually performed by social support networks, as described in the literature. The data analysis was conducted with the tools provided by Critical Discourse Analysis,
\end{abstract}

Endereço para correspondência: Programa de Pós-Graduação da Faculdade de Psicologia, Pontifícia Universidade Católica do Rio Grande do Sul, Av. Ipiranga, 6681, Partenon, Porto Alegre, RS, Brasil 90619900. E-mail: mariana.barcinski@pucrs.br, helena_lermen@yahoo.com.br, cristiane_campani@hotmail.com e bibiana.alt@gmail.com 
which aims at understanding how discursive productions reflect social relations of power. Gender questions were at the core of the analyses performed, once this virtual network is mainly constituted by women. In this sense, we emphasized the unique process of female participants' subjective constitution, as well as the social expectations associated to them in these virtual exchanges. The mentioned expectations characterized this virtual space as eminently feminine. Results show that the exchanges among participants seek to fulfill these families needs', such as emotional, legal, and material support. The referred virtual group reflects the fragility in the social support network of families with incarcerated members, the creative potential of these families, and the alternative possibilities for overcoming the difficulties found in the prison context.

Keywords: Gender, prison, social support network.

\section{Guerreras del Cárce: Una Red Virtual de Apoyo para las Familias de las Personas Privadas de Libertad}

\section{Resumen}

Este artículo tiene como objetivo investigar las funciones desarrolladas por una red informal de apoyo a familiares de presos, caracterizada por una comunidad en una de las mayores redes sociales de relacionamiento del mundo. Durante una semana elegimos postajes realizados en la referida comunidad. Estas han sido agrupadas en categorías interpretativas que remiten a las funciones de una red de apoyo social, como descritas en la literatura. El análisis de los postajes ha sido conducido a partir del Análisis Crítico del Discurso, que busca comprehender de que manera las producciones discursivas reflejan relaciones sociales de poder. Cuestiones de género han estado el tela en el análisis de esta red virtual, compuesta casi que exclusivamente por mujeres. En este sentido, ponemos énfasis en el proceso singular de constitución subjetiva de las participantes y las expectativas sociales vinculadas a ellas en los cambios virtuales que caracterizaron este espacio de compartir como eminentemente femenino. Los resultados apuntan que los cambios efectuados entre los participantes procuran suplir diversas demandas de los familiares, tales como las de apoyo emocional, jurídico y material. La referida comunidad refleja la fragilidad de las redes de apoyo de las familias de presos, la potencia creativa y las posibilidades de superar las dificultades encontradas en el contexto de las prisiones.

Palabras clave: Género, cárcel, red de apoyo social.

No ano de 2013 iniciamos uma pesquisa com familiares de mulheres encarceradas. Durante a coleta de dados em duas unidades prisionais femininas, chamou-nos a atenção a falta de apoio e o despreparo destes familiares em relação às dinâmicas e regras da prisão. Nas filas em dias de visita travávamos conversas com pessoas que tentavam se adequar, a partir de informações não oficiais e da ajuda de outros familiares, às normas institucionais. Conversas que versavam sobre os itens de alimentação, higiene e de vestuário proibidos e permitidos em dias de visitação, bem como dúvidas sobre processos, audiências e recursos relacionados às apenadas faziam parte da rotina nestes dias. As dúvidas recorrentes e o apoio encontrado semanalmente em outros familiares apontavam para a fragilidade das suas redes de apoio social.

A partir do reconhecimento da importância das redes de apoio social para as pessoas privadas de liberdade e da realidade que atesta a fragilidade das redes dos familiares, sobre as quais versaremos adiante, o objetivo do presente estudo é investigar os papéis desempenhados por uma rede informal de apoio para familiares de presos, constituída como uma comunidade ${ }^{2} \mathrm{em}$ uma rede social na internet.

2 Para preservar o sigilo e a privacidade dos seus membros, optamos por não mencionar o nome da comunidade virtual analisada. 
Para a análise desta rede específica, delineamos teoricamente as funções exercidas pelas redes de apoio social, de maneira geral, bem como as especificidades das redes em seu papel na (re)inserção social de pessoas em situação de cárcere.

Questões de gênero estão no foco da análise desta rede virtual, constituída quase que exclusivamente por mulheres. Aspectos sobre a constituição subjetiva das mulheres e as expectativas sociais atreladas a elas - posicionando-as naturalmente como cuidadoras de seus familiares apenados - permeiam as análises.

\section{Redes de Apoio Social}

Por redes de apoio social entende-se o conjunto de pessoas e de instituições que compõem os relacionamentos percebidos como significativos no processo de desenvolvimento dos indivíduos (Brito \& Koller, 1999). A rede de apoio constitui-se como fator protetivo em situações de crise, estresse e mudanças profundas no ciclo de vida dos indivíduos. Seu efeito protetivo está relacionado ao incremento da capacidade de enfrentar adversidades, promovendo a resiliência e o desenvolvimento de mecanismos de adaptação (Brito \& Koller, 1999; Garmezy \& Masten, 1994; Rutter, 1987).

Segundo Sluzki (1997), a rede de apoio assume diferentes funções, que se concretizam a partir do intercâmbio entre seus membros. A primeira delas é a de "companhia social", que se refere à realização conjunta de atividades cotidianas ou estar junto em situações de maior impacto emocional. A função de "apoio emocional" implica na provisão de um espaço de escuta e troca, onde os indivíduos se sentem compreendidos, estimulados e apoiados. Esta função pressupõe o estabelecimento de relações de maior intimidade e de interações mais frequentes. Servir de "guia cognitivo e de conselhos" refere-se ao esclarecimento de expectativas, ao compartilhamento de informações e ao estabelecimento de modelos de papéis. A "regulação (ou controle) social" envolve a mediação de conflitos e a atribuição de responsabilidades, fortalecendo o significado de direitos e deveres entre os membros da rede.
A quinta função da rede -"ajuda material e de serviços" - é desempenhada a partir do conhecimento e da indicação, por parte de alguns membros, de profissionais ou serviços específicos a quem deles necessite. Por fim, a sexta função, de "acesso a novos contatos", envolve o auxílio na abertura e na ampliação da rede dos indivíduos.

Souza, Ribeiro, Atie, Souza e Marques (2008) distinguem redes formais de redes informais de apoio social. As primeiras são constituídas por serviços de atenção à saúde, assistência social, previdência, assistência jurídica, dentre outros. Contextos de carência ou de fragilidade de redes formais de apoio usualmente desencadeiam processos de construção de redes informais, configuradas por relações de proximidade e espontaneidade, tais como aquelas estabelecidas com familiares, vizinhos e amigos.

No que se refere à realidade de pessoas privadas de liberdade, Goffman (1996) aponta que aos efeitos naturais da prisão, tais como o isolamento, a despersonalização e a institucionalização somam-se os efeitos do rompimento de suporte familiar e comunitário, provido pelas redes informais de apoio social. Diante deste rompimento evidencia-se o papel quase que exclusivo assumido pela família de presos no desempenho de funções características das redes formais e informais de apoio social.

No contexto do cárcere os familiares atuam na provisão de suporte emocional (Silva \& Magalhães, 2007) e de insumos básicos (Bassani, 2010), bem como na mediação entre os muros da prisão e o mundo externo (Foltran, 2010). Desta forma, a família opera como principal agente na socialização e no apoio aos indivíduos encarcerados (Medeiros, 2010).

A importância da participação da família neste contexto é ainda enfatizada no que se refere às possibilidades de ressocialização do egresso do sistema prisional. De acordo com Machado (2008), a ressocialização é entendida como sinônimo de reeducação, reforma e reintegração de alguém à sociedade, baseada tanto no trabalho de reestruturação psicossocial do sujeito que cometeu um delito, como na preparação da sociedade para recebê-lo ao final do cumprimento de sua pena. 
Conforme Jardim e Aguinsky (2009), o Estado não só entende que o tratamento penal está vinculado à participação dos familiares, como desloca a eles parte das responsabilidades por este tratamento e pela ressocialização que, por lei, são atribuições do Poder Executivo. Este deslocamento de responsabilidades se expressa desde a expectativa de que a família supra insumos materiais básicos para a sobrevivência do individuo na prisão (como itens de higiene, medicação, etc), de que ofereça contínuo apoio emocional à pessoa privada de liberdade, até de que ela esteja preparada para receber o seu familiar quando do fim do cumprimento de sua pena. É a partir de um cenário claro de falta de informação, apoio e assistência oficiais - da instituição prisão, do judiciário e de outros serviços públicos - que questionamos a delegação à família da responsabilidade pelo processo de ressocialização de egressos do sistema prisional.

Se por um lado as consequências provocadas pela prisão podem ser mais facilmente enfrentadas quando a família oferece suporte ao apenado, por outro a manutenção dos laços familiares no cárcere é prejudicada por variadas questões. Estas dizem respeito à organização das unidades prisionais - como a distância da prisão em relação às moradias dos familiares ou a revista invasiva realizada em dias de visitação -, bem como ao estigma depositado nas famílias de pessoas presas (Buoro, 1998; Silva \& Magalhães, 2007; Spagna, 2008). O impacto destas questões dificultadoras é experimentado de forma particularmente intensa pelos familiares em função da fragilidade de suas próprias redes de apoio social, tanto formais quanto informais.

No caso específico de mulheres que visitam homens em situação de cárcere, a fragilidade de suas redes de apoio social é evidenciada pela criação de redes informais nos horários de visita, quando compartilham sentimentos, dificuldades e sonham juntas que a liberdade do companheiro se concretize em breve (Guimarães et al., 2006). $\mathrm{O}$ espaço prisional passa a se configurar como um lugar de encontro e de troca de experiências, onde as mulheres se apóiam mutuamente.

O presente estudo versa sobre o processo de constituição de uma rede de apoio informal constituída por familiares de pessoas encarceradas, evidenciando que o processo de formação de redes alternativas (quando da ausência de suporte oficial e estatal) é uma estratégia encontrada pelas famílias. Considerando que a referida rede informal é constituída primordialmente por mulheres, é necessário analisarmos o desempenho de suas funções a partir das lentes dos estudos de gênero, enfatizando o papel socialmente esperado de mulheres na manutenção de suas relações afetivas e familiares.

\section{Subjetividade Feminina: O Sofrimento e o Poder das Mulheres}

Ao encontrarmos esta comunidade na internet, deparamo-nos com um espaço virtual construído por mulheres para suprir as lacunas de uma rede de apoio aos detentos. São amigas, familiares, essencialmente companheiras de homens presos que se apropriam deste espaço de contato e de troca com outras mulheres, de forma a expressarem o sofrimento e o poder que sentem ao manter os vínculos afetivos com indivíduos presos, homens em sua maioria.

A perspectiva de autoras como Gilligan (1982) e Miller (1986) enfatiza como ser mulher implica na necessidade de desempenhar papéis que correspondam às demandas dos outros ao redor. A partir de um entendimento psicanalítico, as autoras enfatizam que ser mulher significa ter a habilidade de formar e manter vínculos. Trata-se de uma representação tradicional constitutiva do gênero feminino, que atribui às mulheres estatutos que as definem como seres primordialmente relacionais (Cunha, 1991).

Miller (1986, p. 62) entende que o atendimento aos outros provocaria na mulher a chamada "síndrome da mártir", uma vez que esta negligenciaria seus próprios desejos e necessidades em favor de outrem. A expectativa social do cuidado é também observada no cárcere; dados de pesquisas revelam que as mulheres assumem para si a responsabilidade de acompanhar seus familiares homens presos (Bassani, 2010; Zaluar, 1993).

Quando teorizamos sobre a subjetividade das 'mulheres de bandidos' (termo nativo e apropriado pela literatura, usado para designar 
as mulheres que têm companheiros criminosos ou presos), especialmente sobre as que não abandonam os seus parceiros encarcerados, observamos formas simultâneas de submissão e empoderamento femininos. Ao suportarem as violações impostas pelas instituições prisionais e as dificuldades cotidianas decorrentes do aprisionamento, estas mulheres posicionam seus companheiros presos como dependentes e incapazes de sobreviver ao cárcere sem os seus cuidados (Barcinski, 2008; Bassani, 2010).

Se por um lado a tomada de responsabilidade pela manutenção dos vínculos com seus parceiros encarcerados aponta para a submissão feminina, por outro lado podemos supor que assumir esta função constitua uma forma alternativa de exercício de poder. A posição de mártir assumida por elas nos remete ao ideal de mulher constituído à imagem da Virgem Maria, caracterizado pelo sacrifício e pela abnegação no cuidado do outro, como nos informa o conceito de Marianismo (Barcinski, Capra-Ramos, Weber, \& Dartora, 2013). Esta figura ideal do gênero feminino reúne características valorizadas socialmente, tais como a devoção à família, a renúncia e o servilismo.

Acerca do constrangido poder das mulheres, o controle que elas exercem no espaço privado do lar, ao desempenharem as tarefas relacionadas ao cuidado da casa e da prole, constitui um poder invisível e desvalorizado na esfera pública. É neste sentido que ser identificada como 'mulher de bandido' se constitui em uma escolha de vida que concede protagonismo à construção identitária destas mulheres, configurando-se em um importante recurso para lidar com a invisibilidade dos papéis femininos associados exclusivamente às tarefas domésticas (Barcinski et al., 2013).

Portanto, a 'mulher de bandido' é, ao mesmo tempo, reconhecida como a vítima passiva, que sofre quando seu companheiro é preso, e respeitada pela associação com um homem criminoso e poderoso. Portanto, as motivações e os sentimentos que sustentam o vínculo com um homem preso são ambivalentes e contraditórios (Bassani, 2010), na medida em que envolvem o desejo por esse homem (e por experimentar os ganhos materiais e simbólicos advindos desta as- sociação) e o sofrimento de cumprir a pena junto com ele.

Como discutido anteriormente, Guimarães et al. (2006) destacam a invisibilidade das companheiras de presos no sistema prisional e a inexistência de ações de promoção à saúde e cidadania para essas pessoas. Os autores ressaltam, no entanto, a força das mesmas, que resistem às violações e criam espaços alternativos de denúncia e de busca de igualdade de direitos, para si mesmas e para seus homens.

Interessa-nos, então, reconhecer as funções deste espaço de desabafo, de amparo, de compartilhamento e de escuta constituído pela comunidade virtual em questão, assim como os aspectos da subjetividade feminina que caracterizavam esta rede como um espaço primordialmente de mulheres.

\section{Método}

A comunidade virtual analisada está abrigada em uma das maiores redes sociais de relacionamento do mundo e tem como objetivo promulgado servir de espaço para troca de informações entre familiares de presos. À época da realização do estudo, a comunidade contava com aproximadamente 14.000 participantes. Embora se apresente como um espaço de compartilhamento para quaisquer pessoas que tenham 'alguém preso', a comunidade é claramente destinada ao público feminino, tanto em sua estética, quanto em relação aos conteúdos tratados. Grande parte das mensagens postadas destina-se a mulheres, que se autointitulam 'guerreiras', e versam sobre dúvidas, desabafos e divulgação de informações.

A análise foi realizada sobre o conteúdo das mensagens postadas durante uma semana na comunidade. A necessidade de uma delimitação temporal justificou-se pela quantidade elevada de mensagens postadas na comunidade diariamente. As postagens nos apontam para as diversas funções exercidas por esta rede de apoio informal, bem como para as questões de gênero que caracterizam o seu conteúdo e a forma como são produzidas e recebidas pelos participantes da comunidade. 
Quanto aos recursos de funcionamento da rede social, além da possibilidade de os participantes postarem textos e imagens, eles podem emitir comentários, aprovar/concordar com outros posts através da opção 'curtir' e compartilhar o que os outros postam. Através destas ferramentas, eles demonstram empatia, apoio ou desaprovação. Portanto, para além dos conteúdos verbais publicados, a análise aponta para os recursos interacionais (e suas funções) adotados pelos participantes.

Para procedermos à análise dos dados organizamos o material coletado em categorias definidas a partir do arcabouço teórico sobre redes de apoio social (Sluzki, 1997), anteriormente discutido. Interessou-nos entender de que forma as mensagens postadas sinalizavam o desempenho das funções exercidas por esta rede informal. Como se trata de categorias definidas a priori, a análise nos apontou a dificuldade de inserir o material empírico em apenas uma destas categorias. Uma série de postagens selecionadas poderia ser alocada em mais de uma categoria, evidenciando a complexidade dos dados e a simplificação oriunda de qualquer processo analítico.

Os dados foram analisados a partir da Análise Crítica do Discurso (ACD). Entendendo o discurso como uma prática social política e historicamente situada, a ACD visa a entender de que forma as relações de poder são reproduzidas e contestadas ao micro nível das interações sociais (Van Dijk, 2008). O discurso, portanto, é simultaneamente uma produção individual e social e deve ser analisado como fenômeno que se constitui ao macro e micro níveis.

Ao macro nível analisamos as formas como os participantes se apropriam de discursos hegemônicos na construção das interações travadas na comunidade. Focamos especialmente na reprodução de discursos culturais sobre a subjetividade feminina e sobre a expectativa social do desempenho de certas funções de cuidado. Investigamos, ainda, os discursos apropriados para a construção de identidades normativas na comunidade, tais como a da 'verdadeira guerreira' ou a 'mulher ideal de bandido'.

Ao micro nível foram investigadas as estratégias retóricas e as escolhas linguísticas utiliza- das na construção das mensagens postadas. Tais escolhas nos apontam para a agenda interacional dos participantes, bem como para as sutilezas que fazem desta comunidade um espaço feminino de compartilhamento. Neste nível foram também analisados conteúdos não verbais, que sinalizam a eficácia retórica das trocas efetuadas.

\section{Resultados}

Os trechos publicados na comunidade analisada foram agrupados em seis categorias de análise, que tratam das funções de uma rede de apoio social, tais como descritas pela literatura (Sluzki, 1997). Portanto, são as seguintes categorias analíticas, dentro das quais os conteúdos selecionados foram analisados: companhia social, apoio emocional, guia cognitivo e de conselhos, regulação (ou controle) social, ajuda material e de serviços e acesso a novos contatos.

Os trechos selecionados enfatizam a forma como as trocas realizadas entre os participantes parecem suprir lacunas possivelmente resultantes do enfraquecimento de suas redes de apoio. Para além dos conteúdos que nos informam sobre as funções desta rede informal, discutimos as formas como questões de gênero permeiam as trocas virtuais estabelecidas na comunidade. Como grande parte das trocas na comunidade é efetuada por mulheres, nos referimos 'às participantes', no feminino. Caso a análise verse sobre o discurso de algum participante do sexo masculino, apontamos tal fato. Mantivemos a escrita original das postagens analisadas.

\section{Companhia Social}

As postagens nesta categoria são percebidas como desabafos que buscam o acolhimento de participantes que tenham passado ou que estejam passando por situações semelhantes. Além da companhia subjetiva, experimentada a partir da empatia despertada em relação ao seu sofrimento, através destas mensagens as mulheres angariam a companhia concreta de outras participantes, combinando, por exemplo, de irem juntas visitar os familiares presos em uma mesma unidade prisional. O primeiro post, configurado como um pedido de ajuda, retrata essa ne- 
cessidade de companhia e reforça a comunidade como um espaço de amparo.

"pelo amor de deus alguém visita em [nome do município]????? me ajudem porfavor... sabado meu marido foi pra [nome do presídio] e to precisando de ajuda".

A escolha da expressão "pelo amor de deus" e a quantidade de pontos de interrogação indicam o quanto esta participante necessita das informações solicitadas e a intensidade do seu sofrimento. As respostas ao post apresentam a possibilidade de receber ajuda de outra participante que visita seu companheiro na mesma instituição. A oferta de companhia para o cumprimento da rotina semanal de visitação evidencia a primeira função de uma rede, tal como descrita por Sluzki (1997), a saber, a realização conjunta de atividades cotidianas entre seus membros.

No trecho a seguir, uma mulher pede o apoio (na forma de orações) às demais participantes da comunidade. Seu discurso mescla elementos religiosos e legais, na simultânea menção a Deus e aos direitos humanos, que a participante reconhece como um instrumento de luta pelos direitos de seu marido apenado:

"Queria pedir humildemente que todas leiam com carinho e me ajudem por meio de orações. Venho tendo uma caminhada de 1 ano e 3 meses com meu marido. Dia 27 ele teve um surto, ficou vendo falando coisas sem sentido. . Então os agentes penitenciários jogarem ele no castigo, como se fosse um indisciplinado. Mas até hj ele se encontra no castigo e estou muito aflita, estamos tentando fazer de tudo para tiralo de lá. . . Estou com medo de ir aos Direitos Humanos e piorar tudo de vez. Orem por ele meninas! Todas nós estamos passando por provas muito grande de Deus, e sei que vcs iram me entender mais q qualquer um $q$ passa por isso. Obrigada."

As doze respostas à postagem têm, em sua maioria, o foco na religiosidade, incentivando a participante a ter fé, relatando experiências similares e, portanto, afirmando o compartilhamento de suas vivências no dia a dia do sistema prisional. A literatura nos afirma que a religião configura-se como um potente alicerce de apoio às pessoas que transitam nos espaços prisionais; diante da falta de outras fontes de apoio, os familiares de presos delegam a resolução de seus problemas a Deus (Guimarães et al., 2006).

Acerca das escolhas linguísticas que caracterizam o post, a participante se utiliza de expressões que apelam para o caráter compartilhado da sua experiência: "todas nós estamos passando por provas" e "sei que vcs iram me entender mais q qualquer um q passa por isso". É na afirmação de experiências comuns que a comunidade cumpre seu papel de companhia social às participantes, conferindo a elas um sentido de identidade e pertença a um grupo mais amplo.

No que se refere às relações de poder expressas e negociadas no discurso acima, a participante denuncia que os agentes penitenciários sabiam da inadequação de seus procedimentos. O julgamento sobre o comportamento dos agentes demonstra o reconhecimento da arbitrariedade com que seu marido está sendo tratado na prisão. Ao se referir aos "Direitos Humanos", ela segue apontando para uma consciência de seus direitos, ainda que estes não sejam plenamente exercidos por medo de potenciais retaliações a seu marido. De forma geral, a postagem sinaliza a hierarquia do sistema prisional, dentro do qual os familiares são submetidos ao poder e à arbitrariedade das forças de segurança (Buoro, 1998; Spagna, 2008).

\section{Apoio Emocional}

Os trechos que compõem esta categoria de análise demonstram o desempenho do papel central da comunidade na provisão de apoio emocional aos seus participantes. Os posts aqui analisados configuram-se como manifestações ou pedidos de suporte emocional entre os membros da comunidade. No trecho a seguir a participante comemora a existência da comunidade, afirmando a proximidade e união entre suas participantes, estabelecidas a partir de um objetivo comum: a liberdade de seus familiares.

"Se essa comunidade existe e a cada dia mais aumenta temos que agradecer a nos todas que estamos juntas no dia a dia, nas dores e nas alegrias... E em busca de um 
único sonho LIBERDADE... valeu á todas as guerreiras..."

A segunda postagem dessa categoria nos remete a uma das formas de violência mais percebidas pelos familiares, recorrentemente tratados como suspeitos pela associação com os detentos (Buoro, 1998; Guimarães et al., 2006; Silva \& Magalhães, 2007). As múltiplas violências experimentadas por familiares que transitam em unidades prisionais se transformam, no contexto específico desta comunidade, em elemento de aproximação entre seus membros. No trecho abaixo, a participante desabafa sobre o tratamento dos agentes de segurança durante o procedimento da revista íntima.

"Maior revolta... Cada dia que passa a revista intima ta pior... Daqui a pouco tão mandando a gente fazer quadradinho de 8... Perdendo a noção ..."

O discurso acima se configura como uma denúncia e expressa o desejo da autora de ser apoiada na sua revolta. Percebemos aqui mais uma expressão das relações de poder estabelecidas no sistema prisional. A participante aponta não apenas para o controle operado pelos agentes penitenciários no momento da revista íntima, como denuncia práticas cada vez mais abusivas durante este procedimento de rotina nas prisões. Apesar de ser uma conduta regulamentada, a revista íntima é desmoralizante para o visitante, envolvendo além da sua óbvia exposição física, frequentes agressões verbais perpetradas pelos agentes da segurança (Spagna, 2008). Nas 45 'curtidas' e nos três comentários referentes a este post, as participantes reforçam o caráter humilhante da revista e a indiferença com que são tratadas pelas agentes de segurança.

\section{Guia Cognitivo e de Conselhos}

Agrupados nesta categoria estão os discursos que têm a intenção de fornecer informações, esclarecer expectativas, o que nos aponta para a falta de orientações institucionais claras aos familiares de pessoas apenadas. Consequentemente, a busca por tais informações se dá através do acionamento de redes informais (Souza et al., 2008), que se organizam também para suprir lacunas institucionais.
Perguntas frequentemente postadas por participantes da comunidade dizem respeito às questões judiciais que envolvem o cumprimento da pena de seus familiares. São indagações sobre termos jurídicos, andamento e etapas do processo judicial. No trecho a seguir uma das participantes realiza uma tradução informal de termos utilizados pela Vara de Execuções Criminais (VEC):

"tradução da vec. aguarda mp: o processo esta parado aguardando uma manifestação da promotoria. Aguarda pagamento de RPV: Processo esta aguardando que o governo pague o dinheiro que foi condenado a pagar através de uma requisição de pequeno valor (RPV)."

Conjecturamos que o objetivo deste dicionário informal seja prover informações que promovam a autonomia dos familiares, para que possam consultar e entender o andamento dos processos de seus familiares. No que se refere à análise da relação estabelecida entre o judiciário e o público por ele atendido, nota-se que a comunicação estabelecida é hierarquizada e assimétrica. Os termos específicos do judiciário são de difícil compreensão, o que torna esta comunicação ineficaz (Silveira \&Yunes, 2010), exigindo que os sujeitos leigos aprendam os termos específicos utilizados exclusivamente pela Justiça.

Outro ponto que nos chama a atenção no trecho anterior é, novamente, a forma como os familiares suprem as diversas necessidades de seus parentes presos, tais como a de acompanhamento de suas sentenças. A falha na prestação dos serviços jurídicos dentro das prisões fere os direitos das pessoas presas e obriga os familiares a assumirem para si uma atribuição do Estado (Jardim \& Arguinsky, 2009).

$\mathrm{Na}$ postagem a seguir vemos mais uma evidência da falta de informações e orientações, bem como de uma estrutura adequada para os familiares que visitam pessoas privadas de liberdade. A participante pede enfaticamente - através do uso de letras maiúsculas no seu post - ajuda aos demais membros sobre um meio de transporte e hospedagem, para viabilizar a visita ao seu marido que, provavelmente, foi transferido ou recentemente encarcerado: 
"PRECISO DE AJUDA URGENNTE. Meu marido tá na penita de [nome da penitenciária], não sei nada van, de hotel, to perdida, me socorre...pelo amor de Deus".

\section{Regulação (ou Controle) Social}

Nesta categoria analisamos os discursos produzidos com o intuito de lembrar/afirmar responsabilidades, favorecer a resolução de problemas e indicar modos de agir. As postagens aqui reproduzidas têm o objetivo de nortear a conduta na prisão, orientando sobre a forma como uma mulher que tem um familiar preso deve ser e agir. As 'verdadeiras guerreiras' são instruídas sobre suas responsabilidades no cárcere e sobre os desafios a serem enfrentados em nome do 'amor bandido'. A própria designação de 'guerreira' aponta para a adoção de comportamentos adequados durante o cumprimento da pena de um familiar. Em outras palavras, a concessão do rótulo de 'guerreira' parece resultar do reconhecimento da adequação das condutas de certas mulheres.

A primeira postagem descreve a vida das 'verdadeiras guerreiras', caracterizadas como mulheres que sofrem e se sacrificam em nome do amor:

"a vida de uma guerreira que vive milhões de emoções num só dia . . que cobra de si a perfeição e vive arrumando desculpas para os erros daquele a quem ama. . . e ainda tem que ser forte, prá dar os ombros para quem neles precisa chorar. feliz do homem que por um dia souber, entender - a alma da guerreira!"

Ao todo, 98 mulheres 'curtiram' esta postagem, que está acompanhada de imagens infantis e desenhos de borboletas, ilustrando a fragilidade e a delicadeza que hegemonicamente caracterizam o universo feminino (D’Amorim, 1997). O trecho expressa a autoexigência da perfeição por parte das mulheres que acompanham, apesar de todo o sofrimento, um companheiro encarcerado. Ao cuidar dos seus homens de forma abnegada, a 'guerreira' assume para si a responsabilidade pelos erros de seu companheiro, transformando-se na mulher vitimizada e semidivina destacada pelo conceito de Marianismo
(Stevens, 1973). No trecho analisado, bem como no que se segue, o sacrifício em nome de seus companheiros é enfatizado como a marca da 'guerreira'. O post, portanto, reafirma as expectativas acerca dos modos adequados de agir de mulheres nesta situação.

Ainda enfatizando as peculiaridades da compartilhada 'identidade guerreira', no trecho abaixo a participante estabelece a linha entre elas e outras mulheres que não têm companheiros presos:

"somente as guerreiras podem entender! sou guerreira! - é você que norteia minha luta. - lutar por sua liberdade é o meu ideal! - muitos tentam me derrubar, mas o amor que sinto por você me torna invencivel. quando sua liberdade vier seremos dois na luta de uma vida melhor e o nosso amor será as rochas do nosso castelo."

Este post é acompanhado pela imagem de uma mulher jovem, empunhando duas espadas, caminhando sobre esqueletos no chão, como uma personagem em um cenário de guerra. A ilustração remete às lutas cotidianas das 'guerreiras' recorrentemente citadas pelas participantes da comunidade.

Assim como na postagem anterior, o discurso acima expressa a ambiguidade frequentemente experimentada pelas mulheres, que simultaneamente vivenciam a vitimização e a submissão no cuidado com o outro e o poder adquirido pela afirmação da força e resiliência necessárias ao desempenho deste mesmo cuidado (Barcinski et al., 2013).

Importante salientar a forma como a participante descreve a missão das 'mulheres de bandido' como uma guerra, ao utilizar termos como "minha luta" e ao se referir àqueles que tentam "derrubá-la". É neste trecho que a denominação 'guerreira' ganha seu sentido de forma mais explícita; ao acompanharem seus homens presos estas mulheres travam batalhas em nome do amor e da fidelidade a eles, correndo riscos e vencendo dificuldades impostas.

\section{Ajuda Material e de Serviços}

Nos trechos selecionados nesta categoria de análise, a rede fornece informações sobre 
ajuda profissional específica e serviços, relacionados principalmente às necessidades dos familiares de transporte e de alimentação nos dias de visita. Neste sentido, encontramos a divulgação de informações que orientavam os familiares a acessarem os serviços que viabilizavam as visitas.

A primeira postagem selecionada apresenta a foto de um ônibus de excursão acompanhada da seguinte frase: "Inscrições do Sorteio Aqui". Trata-se da divulgação de um sorteio de passagens com destino aos locais onde há unidades prisionais. No mesmo dia da publicação, o post tinha sido 'curtido' por 69 mulheres e compartilhado 64 vezes. A repercussão do referido sorteio nos aponta para a possível precariedade de recursos financeiros das participantes, bem como para as estratégias informais de enfrentamento desta precariedade (Souza et al., 2008).

A publicação a seguir apresenta o questionamento de uma participante sobre os itens permitidos no "jumbo" em determinada penitenciária. Em linguagem própria do meio prisional, "jumbo" significa o conjunto de alimentos, de roupas e de produtos de higiene que pode ser entregue aos presos pelos seus familiares em dias de visitação.

"lista de jumbo penitenciária [nome], sedex até 8 kilos caixa ate numero 5 do correios sendo um sedex por semana * açúcar $1 \mathrm{kl}$ *nescal 500 grama * bolachas (passa tempo sem recheio, tortinhas, água e sal, maisena) 500 gramas *..."

Este trecho demonstra a arbitrariedade das normas do sistema prisional que determina, por exemplo, a quantidade de açúcar e o tipo de bolacha que podem ser entregues aos presos. Em nossa pesquisa com os familiares, entendemos que tais normativas mudam em função da instituição prisional, obrigando o familiar a se adaptar às regras específicas de cada unidade.

Ainda sobre o fornecimento de alimentos aos detentos, segue o próximo post:

"Pra quem visita em [nomes dos municípios] e so encomendar comidas com a [nome da profissional] ela entrega na pensão que você estiver...".
O trecho acima retrata a forma como uma rede de serviços é constituída em torno das necessidades das famílias no contexto prisional. $\mathrm{O}$ responsável pelo fornecimento da comida não só sabe sobre os alimentos permitidos nas casas prisionais mencionadas, como oferece um serviço de entrega de comida nas pensões em que os familiares se hospedam em dias de visita. Ao analisarmos o conteúdo publicado na comunidade, verificamos que muitos familiares percorrem longas distâncias para visitarem seus parentes presos, necessitando de hospedagens próximas às instituições prisionais. Esta situação constitui uma violação da Lei de Execução Penal (Lei no 7.210, 1984), que prevê no Art. 90 que "A penitenciária de homens será construída, em local afastado do centro urbano, à distância que não restrinja a visitação".

Os locais que vendem lanches próximos às penitenciárias, as empresas de transporte que viabilizam excursões às instituições prisionais e os profissionais que preparam refeições para as visitas dos presos evidenciam um processo de profissionalização do atendimento às famílias, o que certamente gera lucro e oportunidades de emprego em um mercado que se desenvolve simultaneamente ao crescimento da população carcerária. Embora não encontremos na literatura referência a este mercado resultante da situação prisional, esta é uma realidade que atestamos empiricamente em todas as unidades prisionais nas quais realizamos trabalho de campo.

\section{Acesso a Novos Contatos}

Nos trechos selecionados nesta categoria, a rede social oportuniza um espaço de abertura para novas relações. Na medida em que publicam suas dúvidas, seus sentimentos e seus comentários sobre o que outras mulheres escrevem, as participantes estabelecem um canal de troca e de abertura para a formação de novos contatos. A postagem abaixo é realizada por uma mulher cujo marido recém ingressara no sistema prisional:

"Oii, nossaa eu to feeliz demaaais ontem vii meu amooor no julgamento delee . . to chorandoo ate agoora essa saudadee ta me 
matando aos poucooos . . . não sei de nadaa rsrs alguém mee ajudaaa eu sou sozina não tenho ninguem pra me ajudar a família dele naao gosta de miim nao sei oquee faço gentee ... beijaaao Obrigadaa."

O trecho acima se configura como um desabafo e um pedido de ajuda, já que a participante começava a acompanhar seu namorado preso. $\mathrm{O}$ alongamento das vogais ilustra a intensidade dos seus sentimentos e representa um recurso linguístico amplamente utilizado na linguagem virtual (Palmiere, 2005).

$\mathrm{Na}$ última publicação selecionada nesta categoria, encontramos o texto abaixo:

"14.000 mil Likes hahaahaaaa... Que se torne 14.000 mil liberdades."

Observamos que 100 mulheres 'curtiram' esta publicação e alguns dos comentários emitidos expressam a comemoração das 'guerreiras' pelo aumento de participantes na comunidade, evidenciando o fortalecimento desta rede de apoio informal. O significado das 14 mil participantes extrapola aquele espaço virtual organizado, pois as trocas entre as mulheres não se restringem à comunidade. Neste sentido, a magnitude desta rede de apoio, enfatizada na postagem acima, faz sentir seus efeitos na vida cotidiana das mulheres participantes.

\section{Conclusão}

As trocas discursivas estabelecidas na comunidade virtual aqui analisada atestam para a fragilidade das redes de apoio das famílias de pessoas privadas de liberdade, situação corroborada pela literatura e por dados empíricos de nossas pesquisas anteriores. Perdidas entre a desassistência do Estado e as arbitrariedades das instituições prisionais, estas famílias buscam em pessoas e espaços antes desconhecidos as informações e o apoio que não vislumbram em suas existências concretas cotidianas. Portanto, a análise de redes informais de apoio denuncia a forma precária com que familiares acompanham seus entes apenados, contando com seus pares para suportar a dura rotina prisional e para seguirem desempenhando a improvável função de elo ressocializador dos egressos das prisões brasileiras.

No entanto, a comunidade ora analisada também atesta para o potencial de compartilhamento destes familiares e para a criatividade pessoal e coletiva que caracterizam as estratégias adotadas na superação de dificuldades impostas pelo cenário carcerário. São pessoas - mulheres em sua maioria - que compartilham dificuldades profundas e soluções impensáveis para lidar com o isolamento, a solidão e o descaso que marcam suas trajetórias.

Portanto, as 'guerreiras', personagens principais deste espaço forjado a partir de um sofrimento compartilhado, apontam simultaneamente para as múltiplas violações recorrentemente experimentadas por certa parcela da população e para o potencial criador que nasce da margem da sociedade.

Conforme conjecturado, o espaço virtual aqui analisado se configura como um espaço construído por e para mulheres. Os discursos analisados evidenciam as formas particulares como estas mulheres constroem suas identidades, reforçando a expectativa social do cuidado e do amparo femininos. E é primordialmente com outras mulheres que contam para vencerem seus dramas, aqui entendidos naquilo que eles têm de particular e de compartilhado ao mesmo tempo.

\section{Referências}

Barcinski, M. (2008). Women in drug drafficking. Saarbrücken, Germany: VDM Verlag Dr. Müller.

Barcinski, M., Capra-Ramos, C., Weber, J. L. A., \& Dartora, T. (2013). O Marianismo e a vitimização de mulheres encarceradas: Formas alternativas de exercício do poder feminino. EX Aequo, 28.

Bassani, F. (2010). Amor bandido: Cartografia da mulher no universo prisional masculino. Dilemas: Revista de Estudos de Conflito e Controle Social, 4(2), 261-280.

Brito, R., \& Koller, S. H. (1999). Desenvolvimento humano e redes de apoio social e afetivo. In A. M. Carvalho (Ed.), O mundo social da criança: Natureza e cultura em ação (pp. 115-129). São Paulo, SP: Casa do Psicólogo. 
Buoro, A. B. (1998). A cabeça fraca. Familiares de presos frente aos dilemas da percepção dos direitos humanos. Revista USP, 37, 70-81.

Cunha, M. I. P. (1991). A prisão feminina como 'ilha de Lesbos' e 'escola do crime': Discursos, representações, práticas. Cadernos do Centro de Estudos Judiciários, 1(2).

D’Amorim, M. A. (1997). Estereótipos de gênero e atitude acerca da sexualidade em estudos sobre jovens brasileiros. Temas em Psicologia, 5(3), 121-134.

Foltran, P. J. (2010, ago.). A visita nas unidades prisionais e seu papel na mediação do acesso aos direitos da pessoa presa: Uma reflexão acerca das desigualdades de gênero na política penitenciária. In Fazendo Gênero 9 - Diásporas, Diversidades e Deslocamentos (pp. 1-13). Florianópolis, SC: Editora da Universidade Federal de Santa Catarina.

Garmezy, N., \& Masten, A. (1994). Chronic adversities. In M. Rutter, E. Taylor, \& L. Herson (Eds.), Child and adolescent psychiatry (pp. 191-207). Oxford, UK: Blackwell.

Goffman, E. (1996). Manicômios, prisões e conventos. São Paulo, SP: Perspectiva.

Gilligan, C. (1982). In a different voice: Psychological theory and women's development. Cambridge, MA: Harvard University Press.

Guimarães, C. F., Meneghel, S. N., Zwetsch, B. E., Silva, L. B., Grano, M. S., Siqueira, T. P., \& Oliveira, C. S. (2006). Homens apenados e mulheres presas: Estudo sobre mulheres de presos. Psicologia \& Sociedade; 18(3), 48-54. doi:10.1590/S0102-71822006000300007

Jardim, A. C. M. G., \& Aguinsky, B. G. (2009). A inserção dos familiares de apenados nos mecanismos de tratamento penal. In IV Mostra de Pesquisa da Pós-Graduação da PUCRS (pp. 1445-1447). Porto Alegre, RS: Editora da Pontifícia Universidade Católica do Rio Grande do Sul.

Lei $\mathrm{n}^{\circ} 7.210$, de 11 de julho de 1984. (1984, 13 jul.). Institui a Lei de Execução Penal. Diário Oficial da União. Recuperado em 13 de maio, 2013, de http://www.planalto.gov.br/ccivil_03/leis/ 17210.htm

Machado, S. J. (2008). A ressocialização do preso a luz da Lei de Execução Penal (Monografia de conclusão de Curso de Bacharelado em Direto, Universidade do Vale do Itajaí, Biguaçu, SC,
Brasil). Recuperado em 27 de novembro, 2013, de http://siaibib01.univali.br/pdf/Stefano $\% 20$ Jander\%20Machado.pdf

Medeiros, L. L. (2010, abr.). Mulheres e cárcere - Reflexões em torno das redes de proteção social. In Encontro Nacional de História Oral - Testemunhos: História e Política. Recife, PE: Editora da Universidade Federal de Pernambuco.

Miller, J. B. (1986). Towards a new psychology of women. Boston, MA: Beacon Press.

Palmiere, D. T. L. (2005). "Chateando" com jovens e adolescentes: A construção da escrita na internet por grupos de diferentes faixas etárias. Estudos Linguísticos, 34, 503-508.

Rutter, M. (1987). Psychosocial resilience and protective mechanisms. American Journal Orthopsychiatry, 57, 316-331. doi:10.1111/j.1939-0025. 1987.tb03541.x

Silva, R. E., \& Magalhães, C. A. T. (2007). Famílias sentenciadas: Um estudo sobre o impacto da pena sobre as famílias dos presos. Revista de Iniciação Científica Newton Paiva, 90-101.

Silveira, S. B. A. B., \& Yunes, M. A. M. (2010). Interações do ambiente judiciário e famílias pobres: Risco ou proteção às relações familiares? Psicologia em Revista, 16(1), 180-198.

Souza, E. R., Ribeiro, A. P., Atie, S., Souza, A. C., $\&$ Marques, C. C. (2008). Rede de proteção aos idosos do Rio de Janeiro: Um direito a ser conquistado. Ciência e Saúde Coletiva, 13(4), 11531163.

Spagna, L. M. N. (2008). Mulher de bandido: A construção de uma identidade virtual. Revista dos Estudantes de Direito da Universidade de Brasília, 1, 203-229.

Sluzki, C. E. (1997). A rede social na prática sistêmi$c a$. São Paulo, SP: Casa do Psicólogo.

Stevens, E. (1973). Machismo and Marianismo. Society, 1(6), 57-63.

Van Dijk, T. A. (2008). Discurso e poder. São Paulo, SP: Contextos.

Zaluar, A. (1993). Mulher de bandido: Crônica de uma cidade menos musical. Estudos Feministas, $1,135-142$.

Recebido: 05/12/2013

$1^{a}$ revisão: $22 / 04 / 2014$

$2^{a}$ revisão: $29 / 05 / 2014$

Aceite final: 11/06/2014 